\title{
Environmental Lead (Pb) Exposure Versus Fatty Acid Content in Blood and Milk of the Mother and in the Blood of Newborn Children
}

\author{
Irena Baranowska-Bosiacka $^{1}$ - Ida Kosińska ${ }^{1}$ - Dominika Jamiol ${ }^{2}$ - Izabela Gutowska ${ }^{2}$. \\ Adam Prokopowicz $^{3}$ • Ewa Rębacz-Maron ${ }^{4}$ - Marta Goschorska $^{1}$ • Tomasz Olszowski ${ }^{5}$. \\ Dariusz Chlubek ${ }^{1}$
}

Received: 9 July 2015 / Accepted: 14 August 2015 / Published online: 28 August 2015

(C) The Author(s) 2015. This article is published with open access at Springerlink.com

\begin{abstract}
Significant progress in understanding the effects of the neurotoxic action of lead $(\mathrm{Pb})$ in young organisms had led to reduction of "safe" level in the blood $(\mathrm{Pb}-\mathrm{B})$ to $5 \mu \mathrm{g} / \mathrm{dL}$ in children and pregnant women. Prolonged exposure to relatively low levels of $\mathrm{Pb}$, generally asymptomatic and subclinical (i.e., microintoxication), is currently the dominant form of environmental poisoning, and its negative effects on health may appear after many years, e.g., secondary contamination from $\mathrm{Pb}$ bone deposits released in pregnancy. Therefore, the aim of this study was to investigate the effect of environmental exposure (urban areas) of mothers to $\mathrm{Pb}$, on its levels in their milk and blood and in the blood of newborns. Moreover, the aim was to determine the fatty acid profile in the mothers' blood and milk and in the blood of newborns. We also wanted to find if infant birth weight depends on $\mathrm{Pb}$ blood levels, as well as on $\mathrm{Pb}$ and fatty acid levels in the blood and milk of the mothers. Finally, we examined if the mothers' weight and body mass index (BMI) before pregnancy influenced the concentration of $\mathrm{Pb}$ and fatty acid profile in the blood and milk of mothers and in the blood of their children. Analysis of fatty
\end{abstract}

Irena Baranowska-Bosiacka

ika@sci.pam.szczecin.pl

1 Department of Biochemistry and Medical Chemistry, Pomeranian Medical University, Powstańców Wlkp. 72 Str., Szczecin, Poland

2 Department of Biochemistry and Human Nutrition, Pomeranian Medical University, Broniewskiego 24 Str., Szczecin, Poland

3 Institute of Occupational Medicine and Environmental Health, Kościelna 13 Str., 41-200 Sosnowiec, Poland

4 Department of Vertebrate Zoology and Anthropology, University of Szczecin, Wąka 13 Str., 71-415 Szczecin, Poland

5 Department Hygiene and Epidemiology, Pomeranian Medical University, Powstańców Wlkp. 72 Str., Szczecin, Poland acids elaidic (C18:1, 9t), oleic (C18:1, 9c), vaccenic (C18:1, 11t), cis-vaccenic (C18:1, 11c), linoleic (C18:2, cis), $\gamma$ linolenic (C18:3, n-6), $\alpha$-linolenic (C18:3, n-3), arachidonic (C20:4, n-6), eicosapentaenoic (C20:5, n-3), and docosahexaenoic (C22:6, n-3) was conducted by gas chromatography. The concentration of $\mathrm{Pb}$ in the whole blood and milk were determined by atomic absorption spectrometry with graphite furnace atomization and Zeeman correction. Our study established a significant and strong correlation between the content of $\mathrm{Pb}$ in the blood of the mother and the child. This supports the assumption that the transport of $\mathrm{Pb}$ through the placenta is neither regulated nor selective. Environmental maternal exposure to lead resulting in $\mathrm{Pb}-\mathrm{B}$ levels considered safe for pregnant women had no effect on infant birth weight, the concentration of fatty acids in the blood and milk of mothers, or in the blood of newborns. Mothers' weight and BMI before pregnancy had no effect on the concentration of $\mathrm{Pb}$ and studied fatty acid profile.

Keywords $\mathrm{Pb} \cdot$ Fatty acid $\cdot$ Newborn

\section{Introduction}

Lead $(\mathrm{Pb})$ is a metal which is commonly present in the environment and exerts a toxic effect on many organs of the human body [1-3]. The concentration of $\mathrm{Pb}$ in living organisms is closely related to anthropogenic environmental contamination. In developed countries, growing awareness of its effects on human health has resulted in efforts to restrict its use [3, 4]. However, on a global scale, the total level of $\mathrm{Pb}$ emissions into the atmosphere is still high. Moreover, lead compounds are not biodegradable and therefore the current levels of environmental $\mathrm{Pb}$ contamination cannot be effectively reduced [4-6]. 
A primary target for lead is the developing central nervous system. Acute $\mathrm{Pb}$ contamination in children (lead concentration in whole blood- $\mathrm{Pb}-\mathrm{B}>70 \mu \mathrm{g} / \mathrm{dL}$ ), which is currently very rare, can have a dramatic effect on the central nervous system, i.e., brain edema, convulsions, coma, and lead encephalopathy [6]. $\mathrm{Pb}$ poisoning in children on a scale unheard of for decades has been detected in rural northwestern Nigeria. A total of 161 deaths in two villages have been attributed to an incident from May 2009 to May 2010, with hundreds and potentially thousands more people becoming seriously ill $[7,8]$.

Significant progress in understanding the effects of the neurotoxic action of $\mathrm{Pb}$ in young organisms had led to the creation of a system of diagnosis and treatment of lead poisoning and a gradual reduction of "safe" levels in the blood to $10 \mu \mathrm{g} / \mathrm{dL}$ [9, 10]. In children and pregnant women, the permissible dose is $5 \mu \mathrm{g} / \mathrm{dL}$ [3]. At the same time, prolonged exposure to relatively low levels of lead, generally asymptomatic and subclinical (i.e., microintoxication), is currently the dominant form of environmental poisoning and its negative effects on health may appear after many years, e.g., secondary contamination from $\mathrm{Pb}$ bone deposits released in pregnancy [11]. This means that pregnant women should be monitored for $\mathrm{Pb}$ exposure which may result in miscarriage, premature birth, low birth weight, and neonatal malformations [12, 13]. Many studies have also indicated that $\mathrm{Pb}$ levels considered safe can have a neurotoxic effect on the developing brain in the pre- and neonatal period of life $[14,15]$.

A woman's body during pregnancy is burdened with additional functions. It must create the right environment and provide the necessary elements to the developing fetus. One such component is lipids; the lipid profile of a pregnant woman changes to provide energy security for both the mother and child [16]. Of particular importance are the fatty acids that play an important role as building blocks and a source of energy, acting also as a very important component for the proper development of the brain. After birth, the mother's body plays an important role in securing energy through the production of milk with high amounts of fatty acids. Thus, the mother's body during pregnancy and breastfeeding is the only source of fatty acids for the child [17]. At the same time, the same route is used by toxic substances that enter the body of the child, including lead.

Therefore, the aim of this study was to investigate the effect of environmental exposure of mothers to lead, on $\mathrm{Pb}$ levels in their milk and blood and in the blood of newborns. Moreover, the aim was to determine the fatty acid profile in the mothers' blood and milk and in the blood of newborns. We also wanted to find if infant birth weight depends on $\mathrm{Pb}$ blood levels, as well as on $\mathrm{Pb}$ and fatty acid levels in the blood and milk of the mothers. Finally, we examined if the mothers' weight and body mass index (BMI) before pregnancy influenced the concentration of $\mathrm{Pb}$ and fatty acid profile in the blood and milk of mothers and in the blood of their children.

\section{Material and Methods}

\section{Characteristics of the Study Group}

In order to conduct this study, we obtained the consent of the Bioethics Committee at the Pomeranian Medical University in Szczecin (No. BN-001/02/07). Before giving written consent, each patient received full information about the purpose and plan of study.

The study involved 53 female patients of the Clinic of Obstetrics and Perinatology of the Pomeranian Medical University in Szczecin and their newborns. The patients come from urban areas. The survey was conducted from June to August in 2007 and 2008. Forty-nine newborns were born vaginally and four by caesarean section due to the lack of progress of labor. Each pregnant woman was qualified for the study after exclusion of any pathology in pregnancy and coexisting chronic diseases which preceded the pregnancy. The mean age of patients was 29.11 years. During the study, 32 women were primigravidas, while 21 women were multigravidas. None of the women had had multiple pregnancies, while nine subjects had a history of miscarriages. Fifty newborn babies were born after 37 weeks of gestation, two in the 37 th week and one at the 36th week of gestation. All children exhibited functional and morphological maturity, adequate for gestational age (Table 1).

\section{Collection of Blood and Milk}

Blood samples were collected from mothers in the first stage of labor; $9 \mathrm{ml}$ of blood was collected from the cubital vein into tubes containing EDTA as an anticoagulant. Also, $9 \mathrm{ml}$ of blood was collected from umbilical vein into tubes with EDTA after the cord separation. The collected samples were placed at $4{ }^{\circ} \mathrm{C}$ and transported within $10 \mathrm{~min}$ to the laboratory of the Department of Biochemistry of the Pomeranian Medical University. There they were centrifuged at $1800 \times g$ for $10 \mathrm{~min}$ at $4{ }^{\circ} \mathrm{C}$. The plasma obtained by centrifugation was purged with nitrogen, then frozen and stored at $-80^{\circ} \mathrm{C}$ until analysis of a given material.

At 5-6 weeks postpartum, an Avent manual breast pump was used to sample approx. $30 \mathrm{~mL}$ of breast milk. Milk samples were taken in the morning, after feeding. The samples were then transported on ice to the laboratory of the Department of Biochemistry of the Pomeranian Medical University and purged with nitrogen. After this, the samples were frozen at $-80^{\circ} \mathrm{C}$ within $1 \mathrm{~h}$ of collection until analysis. 
Table 1 Descriptive statistics $(n=53)$

\begin{tabular}{lcrrr}
\hline Variable & $x \pm \mathrm{SD}$ & Median & Min-max & CV (\%) \\
\hline Maternal age & $29.11 \pm 4.77$ & 29.00 & $18.00-39.00$ & 0.52103 \\
Neonatal birth weight (g) & $3511.70 \pm 497.75$ & 3570.00 & $2470.00-4350.00$ & 0.38984 \\
Maternal body weight before pregnancy (kg) & $62.94 \pm 12.12$ & 61.00 & $44.00-100.00$ & 0.54997 \\
Maternal prepregnancy BMI & $22.60 \pm 3.85$ & 21.48 & $17.63-34.37$ & 0.54997 \\
Postpartum maternal weight (kg) & $79.69 \pm 13.76$ & 77.00 & $57.70-120.00$ & 0.49581 \\
Postpartum BMI & $28.64 \pm 4.48$ & 27.93 & $21.99-42.52$ & 0.44223 \\
\hline
\end{tabular}

\section{Extraction and Analysis of Fatty Acids}

Lipids from the samples were extracted using the Folch mixture. Then, the samples were hydrolyzed to give fatty acids which were transformed into fatty acid methyl esters (FAMEs). By adding $0.5 \%$ solution of BHT, fatty acids were secured against the oxidation reaction. FAME in hexane solution was injected onto the capillary column (CP-SIL88 $50 \mathrm{M} \times 0.25 \mathrm{~mm}$ ID, film thickness $0.2 \mu \mathrm{m}$, Varian) of the $6890 \mathrm{M}$ Agilent gas chromatograph equipped with an autosampler. FAMEs were mobile in the column in an atmosphere of hydrogen as a carrier gas. The initial temperature was about $100^{\circ} \mathrm{C}$ and maintained for $1 \mathrm{~min}$, then the temperature was increased at a rate of $10^{\circ} \mathrm{C} / \mathrm{min}$ to $180^{\circ} \mathrm{C}$, then at a rate of $3{ }^{\circ} \mathrm{C} / \mathrm{min}$ to $205^{\circ} \mathrm{C}$, and then at a rate of $10^{\circ} \mathrm{C} / \mathrm{min}$ to $220^{\circ} \mathrm{C}$. Identification of geometric and positional fatty acid isomers was carried out on the basis of a comparison of retention times with the Sigma-Aldrich fatty acid standards. The concentrations of fatty acids were determined based on standard curves and expressed in milligrams per milliliter.

Further analyses took into account the following fatty acids: elaidic (C18:1, 9t), oleic (C18:1, 9c), vaccenic (C18:1, 11t), cis-vaccenic (C18:1, 11c), linoleic (C18:2 c), $\gamma$-linolenic (C18:3, n-6), $\alpha$-linolenic (C18:3, n-3), arachidonic (C20:4, n6), eicosapentaenoic (C20: 5, n-3), and docosahexaenoic acid (C22:6, n-3).

\section{Determination of the Concentration of Lead in Blood and in Milk}

The concentration of lead in whole blood (B-Pb) was measured by means of graphite furnace atomic absorption spectrometry. The procedure was based on the Stoepper et al. method for determination of lead in deproteinized blood samples by electrothermal atomization technique [18]. After deproteinization of blood with $0.8 \mathrm{M}$ nitric acid, the samples were analyzed using the Perkin Elmer 4100ZL atomic absorption spectrometer equipped with Zeeman background correction system and autosampler. The calibration was performed by matrix-match calibration standards. The detection limit was $2 \mu \mathrm{g} / \mathrm{L}$ and precision of the method $\sigma \%=4.4$. The results for BCR 194 and BCR 195 certificate reference materials with certificated values of mean $122-130$ and $407-425 \mu \mathrm{g} / \mathrm{L}$ were $123 \pm 5$ and $408 \pm 15 \mu \mathrm{g} / \mathrm{L}(n=23)$, respectively. The analysis was performed at the Institute of Occupational Medicine and Environmental Health in a laboratory that regularly participated in two proficiency tests (Lead and Multielement Proficiency-CDC in Atlanta and METOS ProgramIstituto Superiore di Sanita in Rome) and fulfilled the requirements of the study organizers.

Lead in milk was determined after mineralization $1 \mathrm{~mL}$ of milk with $1 \mathrm{~mL}$ of concentrated nitric acid (Baker InstraAnalyzed) under pressure. The samples were subsequently evaporated nearly to dryness and redissolved to $1 \mathrm{~mL}$ with $0.8 \mathrm{M}$ nitric acid. The resulted solution was analyzed for lead concentration with graphite furnace atomic absorption spectrometry technique (Perkin Elmer 4100ZL) against aqueous standards prepared on diluted $(0.8 \mathrm{M})$ nitric acid. The detection limit was $0.5 \mu \mathrm{g} / \mathrm{L}$ and trueness based on Seronorm (201405) control material (due to the lack of Certified Reference Materials in liquid form for trace elements) with declared value for lead $2.9 \pm 0.2 \mu \mathrm{g} / \mathrm{L}$ was $92 \%$.

\section{Statistical Analysis}

Anthropometric data and concentrations of selected acids in milk and blood of mothers and children were presented as arithmetic means $(x \pm \mathrm{SD})$, medians, and in ranges (maxmin). Based on body mass and height (B-v) of mothers, BMI was calculated $(\mathrm{BMI}=$ body weight $[\mathrm{kg}] /$ height of the body $[\mathrm{m}]^{2}$ ) for the time before pregnancy and after childbirth. The results were interpreted based on the WHO classification, where BMI $\leq 18.49$ is insufficient body weight, BMI 18.50 24.99 is a normal range, $\mathrm{BMI} \geq 25.00-29.99$ denotes overweight, and $\mathrm{BMI} \geq 30.00$ means obesity [19].

The distribution of variables was evaluated using the Shapiro-Wilk $W$ test. As the distribution of variables was not deviated from normal distribution, parametric tests were used for further analyses. Pearson correlation analysis was performed to determine the strength of correlation between the variables. The average concentrations in the analyzed milk, maternal blood, and fetal blood were compared by one-way analysis of variance (ANOVA) for variables with a normal distribution. When the analysis of variance showed that the 
compared means differed significantly, post hoc tests were performed to investigate differences between the means of each group. Comparisons were made with the Tukey's range test. Tests were evaluated at the significance level $p \leq 0.05$.

\section{Results}

\section{Body Mass Index}

Before pregnancy, $11.3 \%(n=6)$ of the surveyed women had an insufficient weight, $64.2 \%(n=34)$ had a weight in a normal BMI range, $17 \%(n=9)$ were overweight, and $7.5 \%(n=4)$ were obese, according to BMI classification.

\section{Pb Concentration in Maternal and Neonatal Blood and in Milk}

The highest average concentration of $\mathrm{Pb}$ was found in maternal blood $(1.290 \mu \mathrm{g} / \mathrm{dL} \pm 0.578)$ and the lowest in milk $(0.174 \mu \mathrm{g} / \mathrm{dL} \pm 1.15)$. On the basis of correlation analysis, we demonstrated a significant and strong correlation between the concentration of maternal blood $\mathrm{Pb}$ and neonatal blood $\mathrm{Pb}$ (Rs $=0.61 ; p \leq 0.0001)$. We also found a weak but statistically significant $(\mathrm{Rs}=0.31 ; p=0.048)$ correlation between the concentration of $\mathrm{Pb}$ in the neonatal blood and the concentration of vaccenic acid (C18: 1, 9t) in maternal blood (Fig. 1).

\section{Elaidic Acid (C18: 1, 9t) in Maternal and Neonatal Blood and in Milk}

The highest average concentration of elaidic acid was determined in milk $(0.273 \mathrm{mg} / \mathrm{mL} \pm 0.19)$. The lowest concentration of the acid was observed in the neonatal blood $(0.002 \mathrm{mg} / \mathrm{mL} \pm 0.001)$.

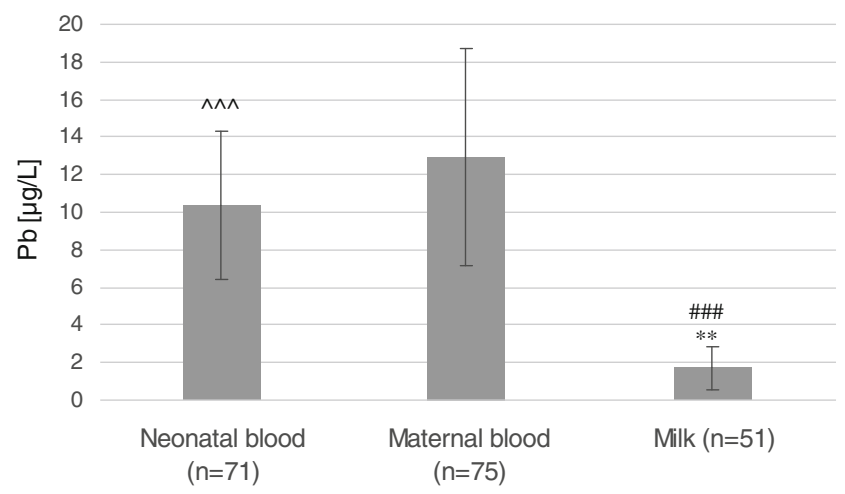

Fig. 1 The concentration of lead $(\mathrm{Pb})$ in maternal and neonatal blood and in milk. ${ }^{*}$ Statistically significant difference between the level of $\mathrm{Pb}$ in the mother's blood and breast milk $(p<0.001)$. \#\#\#Statistically significant difference between the content of $\mathrm{Pb}$ in the neonatal blood and in the milk $(p<0.0001) .{ }^{\wedge \wedge}$ Statistically significant difference between the content of $\mathrm{Pb}$ in the blood of mother and neonate $(p<0.0001)$
Correlation analysis revealed a significant and strong correlation between elaidic and vaccenic acid levels in the mothers' blood ( $\mathrm{Rs}=0.85 ; p=0.0001)$ and milk $(\mathrm{Rs}=0.55 ; p=0.0001)$. A weaker correlation between these acids occurred in the neonatal blood $(\mathrm{Rs}=0.45 ; p=0.001)$. A significant correlation was also found between elaidic acid and $\gamma$-linolenic acid in milk (Rs $=0.48 ; p=0.0001)$ (Table 2$)$.

\section{Oleic Acid (C18: 1, 9c) in Maternal and Neonatal Blood and in Milk}

The highest average level of oleic acid was observed in milk $(15.068 \mathrm{mg} / \mathrm{mL} \pm 6.92)$, while the smallest in the neonatal blood $(0.173 \mathrm{mg} / \mathrm{mL} \pm 0.054)$.

Correlation analysis showed a very strong correlation between oleic acid and C18: 1, 11c in all three cases (milk $\mathrm{Rs}=0.95, p \leq 0.01$; maternal blood Rs $=0.90, p \leq 0.001$; the neonatal blood of Rs $=0.93, p \leq 0.001$ ). A significant $(p \leq 0.0001)$ and also a strong correlation was found between oleic acid and the following acids: linoleic acid in milk $(\mathrm{Rs}=0.90)$, in maternal blood $(\mathrm{Rs}=0.73)$, and neonatal blood $(\mathrm{Rs}=0.80) ; \gamma$-linolenic acid in milk $(\mathrm{Rs}=0.83)$ and in the neonatal blood ( $\mathrm{Rs}=0.55) ; \alpha$-linolenic acid in milk $(\mathrm{Rs}=0.78)$; arachidonic acid in milk $(\mathrm{Rs}=0.91)$, maternal blood $(\mathrm{Rs}=0.63)$, and neonatal blood $(\mathrm{Rs}=0.75)$; eicosapentaenoic acid in milk $(\mathrm{Rs}=0.68)$; and docosahexaenoic in milk $(\mathrm{Rs}=0.71)$, maternal blood $(\mathrm{Rs}=0.62)$, and neonatal blood $(\mathrm{Rs}=0.62)$. A significant $(p=0.0001)$ and a moderately strong correlation occurred between oleic acid and $\gamma$-linolenic acid in the neonatal blood $(\mathrm{Rs}=0.55)$ and $\alpha$-linolenic acid in maternal blood $(\mathrm{Rs}=0.47)$.

\section{Cis-Vaccenic Acid (C18: 1, 11c) in Maternal and Neonatal Blood and in Milk}

Also in the case of cis-vaccenic acid, the highest average concentrations are found in milk $(0.931 \mathrm{mg} / \mathrm{mL} \pm 0.464)$ and the lowest in the neonatal blood $(0.020 \mathrm{mg} / \mathrm{mL} \pm 0.009)$.

On the basis of the correlation analysis, we found showed a significant $(p=0.0001)$ and a strong correlation between the acid $\mathrm{C} 18: 1,11 \mathrm{c}$ and the following acids: linoleic acid in milk $(\mathrm{Rs}=0.84)$, maternal blood $(\mathrm{Rs}=0.65)$, and neonatal blood $(\mathrm{Rs}=0.74) ; \gamma$-linolenic acid in milk $(\mathrm{Rs}=0.78) ; \alpha$-linolenic acid in milk ( $\mathrm{Rs}=0.71)$; arachidonic acid in maternal blood $(\mathrm{Rs}=0.61)$ and neonatal blood $(\mathrm{Rs}=0.76)$; eicosapentaenoic acid in milk $(\mathrm{Rs}=0.64)$; and docosahexaenoic acid in milk (Rs $=0.71)$. There was a significant $(p=0.0001)$ but moderately strong correlation between vaccenic acid in maternal blood $(\mathrm{Rs}=0.47), \gamma$-linolenic acid in the neonatal blood $(\mathrm{Rs}=0.47)$ and docosahexaenoic acid in maternal blood $(\mathrm{Rs}=0.59)$ and neonatal blood $(\mathrm{Rs}=0.51)$. 
Table 2 The content of fatty acids in maternal and neonatal blood and in milk

\begin{tabular}{|c|c|c|c|}
\hline Fatty acid & Neonatal blood $(\mathrm{mg} / \mathrm{mL})$ & Maternal blood (mg/mL) & Milk (mg/mL) \\
\hline Elaidic acid & $0.002 \pm 0.001^{\wedge \wedge}$ & $0.014 \pm 0.009$ & 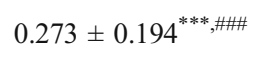 \\
\hline $\begin{array}{l}C 18: 1,9 t \\
\text { Oleic acid }\end{array}$ & $0.173 \pm 0.054^{\wedge \bigwedge}$ & $1.065 \pm 0.305$ & 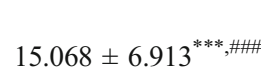 \\
\hline $\begin{array}{l}\text { C18:1, 9c } \\
\text { Vaccenic acid }\end{array}$ & $0.020 \pm 0.009^{\wedge \wedge}$ & $0.079 \pm 0.030$ & $0.931 \pm 0.464^{* * *}$ \\
\hline $\begin{array}{l}\text { C18:1, 11c } \\
\text { Vaccenic acid }\end{array}$ & $0.0003 \pm 0.002^{\wedge \wedge}$ & $0.010 \pm 0.006$ & 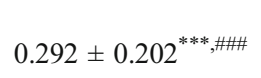 \\
\hline $\begin{array}{l}\text { C18:1, 11t } \\
\text { Linoleic acid }\end{array}$ & $0.135 \pm 0.041^{\wedge \wedge}$ & $1.165 \pm 0.253$ & 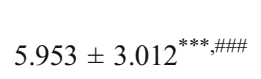 \\
\hline $\begin{array}{l}\text { C18:2, } n-6 c \\
\gamma \text {-Linolenic acid }\end{array}$ & $0.044 \pm 0.002^{\wedge \bigwedge}$ & $0.052 \pm 0.009$ & 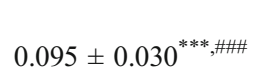 \\
\hline $\begin{array}{l}\text { C18:3, } n-6 c \\
\alpha \text {-Linolenic acid }\end{array}$ & $0.004 \pm 0.003^{\wedge \curlywedge}$ & $0.058 \pm 0.017$ & 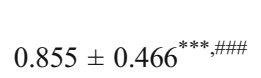 \\
\hline $\begin{array}{l}C 18: 3, n-3 c \\
\text { Arachidonic acid }\end{array}$ & $0.154 \pm 0.043^{\wedge \wedge}$ & $0.267 \pm 0.070$ & $0.225 \pm 0.111^{*}, \# \#$ \\
\hline $\begin{array}{l}C 20: 4, n-6 c \\
\text { Eicosapentaenoic acid }\end{array}$ & $0.005 \pm 0.004^{\wedge \wedge}$ & $0.025 \pm 0.034$ & 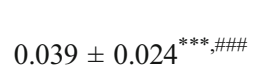 \\
\hline $\begin{array}{l}C 20: 5, n-3 \\
\text { Docosahexaenoic acid } \\
C 22: 6, n-3\end{array}$ & $0.058 \pm 0.022^{\wedge \bigwedge}$ & $0.128 \pm 0.050$ & $0.127 \pm 0.066^{\# \# \#}$ \\
\hline
\end{tabular}

$\wedge \wedge$ Statistically significant difference in the fatty acid level between the maternal and neonatal blood $(p<0.0001)$; $* * *$ statistically significant difference in the fatty acid level between the maternal blood and milk $(p<0.0001)$; *statistically significant difference in the fatty acid level between the maternal blood and milk $(p<0.01)$; \#\#\#statistically significant difference in the fatty acid level between the neonatal blood and milk $(p<0.01)$; \#\#statistically significant difference in the fatty acid level between the neonatal blood and milk $(p<0.001)$

\section{Vaccenic Acid (C18: 1, 11t) in Maternal and Neonatal Blood and in Milk}

The highest average concentration of vaccenic acid has been identified in milk $(0.292 \mathrm{mg} / \mathrm{mL} \pm 0.202)$ and the smallest in the neonatal blood $(0.0003 \mathrm{mg} / \mathrm{mL} \pm 0.002)$.

The correlation between the concentration of vaccenic acid concentrations and other acids was placed in U.S. preceding acids.

\section{Linoleic Acid (C18: 2, cis) in Maternal and Neonatal Blood and Milk}

As in all previous acids, also in the case of linoleic acid, the highest average concentration is found in milk $(5.953 \mathrm{mg} / \mathrm{mL}$ $\pm 3.012)$ and the lowest in the neonatal blood $(0.135 \mathrm{mg} / \mathrm{mL}$ $\pm 0.41)$.

Correlation analysis revealed a significant $(p=0.0001)$ and strong correlation between linoleic acid and the following acids: $\gamma$-linolenic acid in milk ( $\mathrm{Rs}=0.76) ; \alpha$-linolenic acid in milk $(\mathrm{Rs}=0.80)$ and maternal blood $(\mathrm{Rs}=0.66)$; arachidonic acid in milk ( $\mathrm{Rs}=0.86)$, maternal blood $(\mathrm{Rs}=0.64)$, and neonatal blood $(\mathrm{Rs}=0.71)$; eicosapentaenoic acid in milk $(\mathrm{Rs}=0.60)$; and docosahexaenoic acid in the neonatal blood $(\mathrm{Rs}=0.69)$. A significant $(p=0.0001)$ but weaker correlation was found between linoleic acid and $\gamma$-linolenic acid in the neonatal blood $(\mathrm{Rs}=0.47), \alpha$-linolenic acid in neonatal blood $(\mathrm{Rs}=0.55)$, and docosahexaenoic acid in maternal blood $(\mathrm{Rs}=0.56)$.

\section{$\gamma$-Linolenic Acid (C18: 3, n-6 Gamma) in Maternal and Neonatal Blood and in Milk}

The greatest concentration of $\gamma$-linolenic acid was determined in milk $(0.095 \mathrm{mg} / \mathrm{mL} \pm 0.030)$, and the lowest in the neonatal blood $(0.044 \mathrm{mg} / \mathrm{mL} \pm 0.002)$.

Based on the analysis of the correlation, a significant $(p=0.0001)$ and strong correlation was observed between $\gamma$-linolenic acid and arachidonic acid in milk $(\mathrm{Rs}=0.78)$ and between $\gamma$-linolenic acid and eicosapentaenoic acid in milk ( $\mathrm{Rs}=0.60)$. A significant $(p=0.0001)$ but statistically less strong correlation occurred between $\gamma$-linolenic acid and $\alpha$-linolenic acid in milk $(\mathrm{Rs}=0.54)$, arachidonic acid in the maternal blood $(\mathrm{Rs}=0.51)$, and docosahexaenoic acid in milk $(\mathrm{Rs}=0.49)$.

\section{$\alpha$-Linolenic Acid (C18: 3, n-3 Linolenic Acid) in Maternal and Neonatal Blood and in Milk}

The highest average level of $\alpha$-linolenic acid was determined in milk $(0.855 \mathrm{mg} / \mathrm{mL} \pm 0.466)$ while the lowest in neonatal blood $(0.004 \mathrm{mg} / \mathrm{mL} \pm 0.003)$. 
Correlation analysis revealed a significant $(p=0.0001)$ and a strong correlation between the $\alpha$-linolenic acid and arachidonic acid in milk $(\mathrm{Rs}=0.71)$, eicosapentaenoic acid in milk $(\mathrm{Rs}=0.67)$, and docosahexaenoic acid also in milk $(\mathrm{Rs}=0.63)$. A significant $(p=0.0001)$ but weaker correlation was found between $\alpha$-linolenic acid and docosahexaenoic acid in maternal blood $(\mathrm{Rs}=0.47)$ and neonatal blood $($ Rs $=0.55)($ Table 2).

\section{Arachidonic Acid (C20: 4, n-6) in Maternal and Neonatal Blood and in Milk}

Unlike previous acids, the highest average concentration of arachidonic acid was fond in maternal blood $(0.267 \mathrm{mg} / \mathrm{mL}$ $\pm 0.070)$, while the lowest in neonatal blood $(0.154 \mathrm{mg} / \mathrm{mL}$ \pm 0.043 ).

Correlation analysis showed a significant $(p=0.0001)$ and strong correlation between the arachidonic acid and eicosapentaenoic acid in milk $(\mathrm{Rs}=0.71)$ and docosahexaenoic acid in milk $(\mathrm{Rs}=0.77)$ and maternal blood (Rs $=0.75)$. An equally significant $(p=0.0001)$ but weaker correlation was determined between the arachidonic acid and docosahexaenoic acid in neonatal blood of the child $(\mathrm{Rs}=0.58)($ Table 2$)$.

\section{Eicosapentaenoic Acid (C20: 5 n-3) in Maternal and Neonatal Blood and in Milk}

In the case of eicosapentaenoic acid, the highest average concentration was observed in milk $(0.039 \mathrm{mg} / \mathrm{mL} \pm 0.024)$, while the lowest in neonatal blood $(0.005 \mathrm{mg} / \mathrm{mL} \pm 0.004)$.

Correlation analysis showed a significant and strong correlation between eicosapentaenoic acid and docosahexaenoic acid in milk $(p=0.0001, \mathrm{Rs}=0.78)($ Table 2$)$.

\section{Docosahexaenoic Acid (C22: 6, n-3) in Maternal and Neonatal Blood and in Milk}

The highest concentration of docosahexaenoic acid was found in maternal blood $(0.128 \mathrm{mg} / \mathrm{mL} \pm 0.050)$. The lowest concentration of the acid occurred in neonatal blood $(0.058 \mathrm{mg} / \mathrm{mL}$ $\pm 0.022)$. There were no significant correlations between the studied parameters for docosahexaenoic acid (Table 2).

\section{Discussion}

This is the first study on the effect of environmental exposure to $\mathrm{Pb}$ on the fatty acid profile in the mothers' blood and milk and in the blood of newborns. Our results showed, that $\mathrm{Pb}-\mathrm{B}$ values in the mothers blood was below levels considered safe for pregnant women, e.g. below $5 \mu \mathrm{g} / \mathrm{dL}$ [3]. Pb content in all blood samples from the newborns were also inside the safe levels. This indicates that mothers were not exposed to high $\mathrm{Pb}$ concentrations before and during pregnancy. They were representative for the area characterized by moderate $\mathrm{Pb}$ levels in the environment. The results are consistent with previous studies on the transport of $\mathrm{Pb}$ through the placenta to the cord blood [20,21]. Our study also showed a significant and strong correlation between $\mathrm{Pb}$ levels in the blood of the mother and the child. This supports the idea that the transport of $\mathrm{Pb}$ through the placenta is neither regulated nor selective [21]. A woman's body during pregnancy is burdened with additional demands. It must create the right conditions for the growth of the fetus and provide it with all the elements necessary for development-hence the importance of a correct diet. One of the nutrients necessary for the proper development of the fetus is lipids. The lipid profile of a pregnant woman changes to ensure energy security for both her and the fetus. The mother's body increases its absorption of lipids and raises their concentration in the blood. The concentrations of total cholesterol and VLDL, LDL, HDL, and TG increase along with the development of gestation [16].

In the body of the developing fetus, fatty acids are transferred mainly to the cytoplasm of fat cells, where they can be subjected to oxidation, multiplication of double bonds in the molecule, or extension of the molecule. The other main site of fatty acid occurrence is cellular structures, especially phospholipids. The type of acid that is built in phospholipids decides the fluidity of the membrane structure and function of membrane receptors and enzymes. Studies have shown that dietary trans-unsaturated fatty acids (TFAs) are more actively incorporated into the cell membrane than cis-unsaturated fatty acids [17]. Although placental transfer of saturated and cisunsaturated fatty acids has been demonstrated in rats, very few studies have investigated the placental transport of trans-fatty acids, and the obtained results are contradictory [22-24].

A study of Larqué et al. [25] shows that trans-fatty acids are incorporated into plasma and liver microsomes of pregnant rats in high concentrations and according to their profile and content in the diets; however, this is shown not to occur in the brain. The placenta also incorporates high amounts of transisomers into its structure. However, this barrier is not completely impermeable, inasmuch as a number of trans-fatty acids cross the barrier and accumulate in the liver of the fetus, showing a clear exposure of fetal tissues to maternal dietary trans-fatty acids. This reflects the protective mechanisms serving to limit the incorporation of TFAs in the central nervous system $[25,26]$.

However, it is uncertain whether exposure to TFA in early human life has adverse consequences. Studies on animals show different explanations of TFA incorporation in human tissues and the biological consequences of this process in the neonatal period and during lactation. It has been shown that animals born by mothers fed a diet rich in TFA had significantly lower concentrations of those acids in their blood 
compared to maternal blood. Some amounts of trans-FAs reach the placenta but are probably catabolized in fetal tissues or replaced by the newly synthesized FAs [26]. In our research, we also observed a much lower concentration of FAs in the children's blood compared to maternal blood. This may be a confirmation of the proposition that FA are metabolized in placenta tissues or that there are some mechanisms inhibiting the transport of high FA concentrations through the placenta. In our study, however, we found no correlation between individual fatty acids in the mother's blood and baby's blood.

The concentration of fats in milk increases significantly during breast-feeding. The main fatty acids in milk are saturated fatty acids, half of which is palmitic acid. These acids can be synthesized de novo in the tissues of the body or may be provided with the diet of mother. Cis-unsaturated fatty acids are mainly represented by 18:1 9c (oleic acid). Although monoene fatty acids are not essential and can be synthesized, their intake with diet may have positive physiological effects on the fluidity of cell membranes and cholesterol metabolism.

The content of trans-unsaturated fatty acids in human breast milk is estimated to be $4.4 \%$, with the main transisomer being $\mathrm{C} 18: 111 \mathrm{t}$ (vaccenic acid), followed by isomers 14:1t, 16:1t, and 20:1t [27]. The concentrations of unsaturated fatty acids in our study showed the highest concentration of oleic acid and the smallest of eicosapentaenoic acid (Table 2). Vaccenic and elaidic acids had the highest concentrations among trans-unsaturated fatty acids.

The types of lipids present in breast milk depend on the diet $[17,28]$, similar to the total amount of TFA. Their presence may limit the availability of long-chain polyunsaturated fatty acids (LC-PUFAs). Because LC-PUFAs are very important for the early development of eyesight and cognitive abilities, factors that reduce their availability after birth are a serious issue [29]. However, until recently, this role of LC-PUFAs has been controversial. Some studies show an inverse correlation between the concentration of TFA 18:1 and PUFAs n-3 and n6 in breast milk and blood of the newborn. Desci et al. [28] showed that in the lipids of umbilical vascular walls an increased concentration of TFA C18:1 is associated with decreased levels of docosahexaenoic acid. This relationship has been confirmed by other authors, for example Elias and Innis [30]. However, other studies show no connection between these two groups of fatty acids, similar to the results of the present study [31]. A negative correlation between TFAs and PUFAs results from the inhibition of LC-PUFA synthesis by TFA, which is confirmed in research conducted on rats and in vitro on rat tissues and human fibroblasts. However, in that case, it was impossible to make a clear statement because of other works which show that the inhibitory action of TFAs is observed only at high levels which are not normally found in the diet [17].
The inhibitory effect is postulated to be associated with disorders of enzymatic conversion of linoleic acid to arachidonic acid, documented in studies on animal models and in human fibroblasts in vitro. It is assumed that TFAs are incorporated into the cell membrane and inhibit the metabolic conversion of $18: 2 n-6$ and $18: 3 n-3$ to the longer chains of n- 6 and n-3 PUFAs. A significant decrease of n-6 and n-3 acids observed in this study represents the effect of TFAs on the desaturation and chain elongation of 18:2n-6 and 18:3n-3, which indicates a loss of metabolic properties [32]. The current study demonstrates that there is an inverse correlation not only between TFAs and LC-PUFAs as well as between TFAs and the substrate/product ratio in the synthesis of LC-PUFAs but also between TFAs and linoleic acid in cholesterol esters. However, it is not known yet whether this could have a connection with the inhibition of the biosynthesis or if the result is a combination of these two processes [29].

One of the dependencies that we investigated in this study was the correlation between the studied FAs and BMI before and after pregnancy. The results of our study showed no such correlation. FAs did not correlate with maternal body weight before and after pregnancy. This may have been due to the fact that the BMI of most of the surveyed women did not indicate obesity and were within the normal range BMI $=18.5-24.99$. Other publications, however, show a correlation between BMI before pregnancy and mother's lipid profile during the initial phase of gestation, which also correlated with the child's obesity [33].

Also controversial is the question of the effects of inhibition of the synthesis of linoleic acid and $\alpha$-linolenic acid by TFAs. It is assumed that it may result in defects in fetal development and low birth weight. Some authors claim that inhibiting the synthesis of the aforementioned acids results in a shorter pregnancy, having no effect on birth weight and length of the body of the newborn. Others believe that the result is lower birth weight and length of the body with a normal duration of pregnancy.

A third position assumes that these three values are reduced, i.e. that the effects include low birth weight, shorter body length, and a shorter duration of pregnancy. On this basis, it is difficult to determine what exactly is affected by TFA-induced inhibition of the synthesis of linoleic acid and alpha-linolenic acid, although a negative impact on fetal development is visible [17]. The results of our study showed no correlation between the studied FAs and birth weight.

In this study, no correlation was observed between $\mathrm{Pb}$ blood levels and the tested FAs, except for one case of a weak correlation between the $\mathrm{Pb}$ in the blood of the newborn and elaidic acid concentration in maternal blood. It is difficult to discuss the obtained results because there are no studies on the relationship between the concentration of blood FAs and $\mathrm{Pb}$ in available literature. There are only reports on the link between psychosocial disorders of children and the concentrations of 
$\mathrm{Pb}$ and FAs, which indicate a possible relationship between these two variables. The authors of that paper showed that children with elevated levels of blood $\mathrm{Pb}$ exhibited disorders in psychosocial functioning at school and at home. The same behavior was revealed in children with a reduced concentration of arachidonic acid, $\gamma$-linolenic acid, eicosapentaenoic acid (EPA), and docosahexaenoic acid (DHA) levels [33]. To find a definite link between psychosocial disorders of children and the concentrations of $\mathrm{Pb}$ and FAs, further research is required to study correlations of $\mathrm{Pb}$ and TFA and the mechanisms of their actions in the human body.

In our study, we found no correlation between maternal blood $\mathrm{Pb}$ and low birth weight. This was probably due to the low concentration of $\mathrm{Pb}$ in the blood of mothers, insufficient to induce any such effect.

Exposure of children, adolescents, and adults to $\mathrm{Pb}$ negatively correlates with BMI and obesity [34, 35]. Also our study confirmed this correlation between the concentration of $\mathrm{Pb}$ in the blood of mothers and mothers' BMI before pregnancy.

\section{Conclusion}

Our study established a significant and strong correlation between the content of $\mathrm{Pb}$ in the blood of the mother and the child. This supports the assumption that the transport of $\mathrm{Pb}$ through the placenta is neither regulated nor selective. Environmental maternal exposure to lead resulting in $\mathrm{Pb}-\mathrm{B}$ within levels previously considered safe for pregnant women, i.e., $5 \mu \mathrm{g} / \mathrm{dL}$, had no effect on the concentration of fatty acids in the blood and milk of mothers or in the blood of newborns.

Conflict of Interest The authors declare that they have no competing interests.

Open Access This article is distributed under the terms of the Creative Commons Attribution 4.0 International License (http:// creativecommons.org/licenses/by/4.0/), which permits unrestricted use, distribution, and reproduction in any medium, provided you give appropriate credit to the original author(s) and the source, provide a link to the Creative Commons license, and indicate if changes were made.

\section{References}

1. CDC 2004 (Center for Disease control and Prevention). National Center for Environmental Health. A review of evidence of health effects of blood lead levels $<10 \mu \mathrm{g} / \mathrm{dL}$ in children. Atlanta. http:// www.cdc.gov/nceh/lead/ACCLPP/meetingMinutes/ lessThan10MtgMAR04.pdf Access 26 March 2015

2. CDC (Centers for Disease Control and Prevention) (2005) National Center for Environmental Health. Preventing lead poisoning in young children. Atlanta
3. CDC (Centers for Disease Control and Prevention) (2012) Sources of lead. Available: http://www.cdc.gov/nceh/lead/tips/sources.html Access 26 March 2015; EP (Environmental Protection) (2005) The restriction of the use of certain hazardous substances in electrical and electronic equipment regulations No. 2748. http:// www. legislation.gov.uk/uksi/2005/2748/pdfs/ uksi_20052748_en.pdf Access 26 March 2015

4. WHO (World Health Organization), 2010. Preventing disease through healthy environments. Available: http://www.who.int/ ipcs/features/10chemicals_en.pdf Access 26 March 2015; EP (Environmental Protection) (2009) The restriction of the use of certain hazardous substances in electrical and electronic equipment (amendment) regulations, No. 581. http://www.legislation.gov.uk/ uksi/2009/581/pdfs/uksi_20090581_en.pdf Access 26 March 2015

5. EU. 2008 (European Commission). Institute for Health and Consumer Protection Toxicology and Chemical Substances (\& ECB). Opinion of the TC NES on the Environment Part of Industry Voluntary Risk Assessments on Lead and Lead Compounds. http://echa.europa.eu/doc/trd_substances/VRAR/ Lead/tcnes_opinion/tcnes_opinion_env.pdf Access 26 March 2015

6. CDC (Centers for Disease Control and Prevention), 2002. Managing elevated blood lead levels among young children: recommendations from the Advisory Committee on Childhood Lead Poisoning Prevention. Atlanta, GA:U.S. Department of Health and Human Services, CDC. Available: http://www.cdc.gov/nceh/lead/ casemanagement/casemanage_main.htm Access 26 March 2015

7. Moszyński P (2010) Lead poisoning in Nigeria causes "unprecedented" emergency. BMJ 341:c4031

8. Lo YC, Dooyema CA, Neri A, Durant J, Jefferies T, MedinaMarino A, de Ravello L, Thoroughman D, Davis L, Dankoli RS, Samson MY, Ibrahim LM, Okechukwu O, Umar-Tsafe NT, Dama AH, Brown MJ (2012) Childhood lead poisoning associated with gold ore processing: a village-level investigation-Zamfara State, Nigeria, October-November 2010. Environ Health Perspect 120(10):1450-1455

9. PubChem Public Chemical Database; http://pubchem.ncbi.nlm.nih. gov/compound/5352425? from=summary\#section=Toxicity, Access 26 March 2015

10. WHO, http://www.who.int/ipcs/features/lead.pdf Access 18 November 2013

11. Chelchowska M, Ambroszkiewicz J, Jablonka-Salach K, Gajewska J, Maciejewski TM, Bulska E, Laskowska-Klita T, Leibschang J (2013) Tobacco smoke exposure during pregnancy increases maternal blood lead levels affecting neonate birth weight. Biol Trace Elem Res 155:169-175

12. WHO. Environmental Health Criteria 165. Inorganic lead. Geneva. 1995

13. Afeiche M, Peterson KE, Sánchez BN, Schnaas L, Cantonwine D, Ettinger AS, Solano-González M, Hernández-Avila M, Hu H, Téllez-Rojo MM (2012) Windows of lead exposure sensitivity, attained height, and body mass index at 48 months. J Pediatr 160: 1044-1049

14. Baranowska-Bosiacka I, Strużyńska L, Gutowska I, Machalińska A, Kolasa A, Kłos P, Czapski GA, Kurzawski M, Prokopowicz A, Marchlewicz M, Safranow K, Machaliński B, Wiszniewska B, Chlubek D (2013) Perinatal exposure to lead induces morphological, ultrastructural and molecular alterations in the hippocampus. Toxicology 303:187-200

15. CDC (Centers for Disease Control and Prevention), 2007. Interpreting and managing blood lead levels $<10 \mu \mathrm{g} / \mathrm{dL}$ in children and reducing childhood exposures to lead: recommendations of CDC's Advisory Committee on Childhood Lead Poisoning Prevention. MMWR Recomm Rep 56, 1-16. Available: http:// www.cdc.gov/mmwr/preview/mmwrhtml/rr5608a1.htm Access 26 March 2015 
16. Lippi G, Albiero A, Montagnana M, Salvagno GL, Scevarolli S, Franchi M, Guidi GC (2007) Lipid and lipoprotein profile in physiological pregnancy. Clin Lab 53(3-4):173-177

17. Jamioł-Milc D, Stachowska E, Chlubek D (2010) The effects of dietary trans fatty acids in pregnancy and lactation. Annales AMS 56:21-27

18. Stoeppler M, Brandt K, Rains TC (1978) Contribution to automated trace analysis. Part II. Rapid method for the automated determination of lead in whole blood by electrothermal atomic-absorption spectrophotometry. Analyst 103:714-722

19. Physical status (1995) The use and interpretation of anthropometry. Report of a WHO expert committee. WHO Tech Rep Ser Geneva 854:1-452

20. Krzywy I, Krzywy E, Pastuszak-Gabinowska M, Brodkiewicz A (2010) Lead - is there something to be afraid of? Annales AMS 56: $118-128$

21. Suprewicz K, Kozikowska I, Chrobaczyńska-Dylag M, Gał A, Piekarz A, Sikora J, Sławska H, Stawarz R (2013) Effects of the cigarette smoking on the newborn clinikalclinical parametrsparameters and the accumulation of cadmium and lead in the placenta of women from Upper Silesia. Ginekol Pol 84: 776-780

22. Johnston PV, Kummerow FA, Walton GH (1985) Origin of the trans fatty acids in human tissue. Proc Soc Exp Biol Med 99:735736

23. Senti FR (1985) Health aspects of dietary trans fatty acids. In: Senti FR (ed) Life Sciences Research Office. Federation of the American Societies for Experimental Biology, Bethesda, pp. 1-56

24. Koletzko B, Muller J (1990) Cis- and trans-isomeric fatty acids in plasma lipids of newborn infants and their mothers. Biol Neonate 57:172-178

25. Larque E, Pérez-Llamas F, Puerta V, Girón MD, Suárez MD, Zamora S, Gil A (2000) Dietary trans fatty acids affect docosahexaenoic acid concentrations in plasma and liver but not brain of pregnant and fetal rats. Pediatr Res 47(2):278-283
26. Larque E, Zamora S, Gil A (2001) Dietary trans fatty acids in early life: a review. Early Hum Dev 65:31-41

27. Koletzko B, Mrotzek M, Bremer HJ (1988) Fatty acid composition of mature human milk in Germany. Am J Nutr 47:954-959

28. Berghaus TM, Demmelmair H, Koletzko B (1998) Fatty acid composition of lipid classes in maternal and cord plasma at birth. Eur J Pediatr 157:763-768

29. Decsi T, Burus I, Molnár S, Minda H, Veitl V (2001) Inverse association between trans isomeric and long-chain polyunsaturated fatty acids in cord blood lipids of full-term infants. Am J Clin Nutr 74: 364-368

30. Elias SL, Innis SM (2001) Infant plasma trans, n-6, and n-3 fatty acids and conjugated linoleic acids are related to maternal plasma fatty acids, length of gestation, and birth weight and length. Am J Clin Nutr 73(4):807-814

31. Mahomed K, Williams M, King I, Mudzamiri S, Woelk G (2007) Erythrocyte omega-3, omega-6 and trans fatty acids in relation to risk of preeclampsia among women delivering at Harare Maternity Hospital, Zimbabwe. Physiol Res 56:37-50

32. Kummerow FA, Zhou Q, Mahfouz MM, Smiricky MR, Grieshop CM, Schaeffer DJ (2004) Trans fatty acids in hydrogenated fat inhibited the synthesis of the polyunsaturated fatty acids in the phospholipid of arterial cells. Life Sci 74:2707-2723

33. Gademan M, Vermeulen M, Oostvogels A, Roseboom TJ, Visscher T, van Eijsden M, Twickler MT, Vrijkotte TG. (2014) Maternal prepregnancy BMI and lipid profile during early pregnancy are independently associated with offspring's body composition at age 5-6 years: the ABCD study. PLoS One 9(4):e94594

34. Scinicariello F, Buser MC, Mevissen M, Portier CJ (2013) Blood lead level association with lower body weight in NHANES 19992006. Toxicol Appl Pharmacol 273(3):516-523

35. Jain RB (2013) Effect of pregnancy on the levels of blood cadmium, lead and mercury for females aged 17-39 years old. J Toxicol Environ Health A 76:58-69 